\title{
Naturezas da arte - diálogos entre tempos na floresta
}

\author{
Isabela Frade' e Alexandre Guimarães"
}

Resumo: Compartilhamos reflexões sobre poéticas sensíveis ao tema da natureza, demonstrando que já há algum tempo, diversas formas de ações artísticas vêm envolvendo a floresta urbana carioca. Entre viajantes e contemporâneos, pensamos o encontro da arte com a exuberância da Mata Atlântica, promovendo diálogo entre processos, modos de comunicação e agenciamentos na perspectiva da restauração equilibradora.

Palavras-chave: Floresta. Poéticas Imersivas. Artistas Viajantes. Rio de Janeiro.

\section{Natures of art - dialogues between times in the forest}

\begin{abstract}
Sharing reflections on poetics sensitive to the theme of nature, we demonstrate that for some time now, various forms of artistic actions have been involving the urban forest in Rio de Janeiro. Among travelers and contemporaries, we think of the meeting of art with the exuberance of the Atlantic Forest, promoting a dialogue between processes, modes of communication and agencies in the perspective of balanced restoration.
\end{abstract}

Keywords: Forest. Immersive Poetics. Traveling Artists. Rio de Janeiro.

I Docente do Centro de Artes da Universidade Federal do Espírito Santo e no PPGARTES UERJ, onde integra alinha Arte, Pensamento e Performatividade. Educadora, ceramista e artista, possui doutorado em Ciências da Comunicação pela ECA USP. Pesquisadora e Docente do Programa de Pós-Graduação em Arte e Cultura Contemporânea PPGARTES/ UERJ - R. São Francisco Xavier, 524 - Maracanã, Rio de Janeiro - RJ, 20550-013. E-mail: isabelafrade@gmail.com. ORCID: https://orcid.org/0000-0001-5224-6633. Lattes iD: http://lattes.cnpq.br/0576968930348730. Rio de Janeiro, RJ, Brasil.

II Professor de Artes Visuais do Colégio Pedro Il e doutor pelo Programa de Pós-Graduação em Artes (PPGARTES) da Universidade do Estado do Rio de Janeiro (2017); Mestre em Arte e Cultura Contemporânea também pelo PPGARTES (2011). Pós-graduado em História da Arte e Arquitetura no Brasil pela Pontifícia Universidade Católica do Rio de Janeiro (2002). Graduado em Artes, em Licenciatura Plena, com habilitação em História da Arte pela Universidade do Estado do Rio de Janeiro (1999). Atualmente compõe a equipe de Pós-Graduação SABERES E FAZERES NO ENSINO DE ARTES VISUAIS do Colégio Pedro II e integra o grupo de pesquisa Observatório de Comunicação Estética (OCE/ CNPQ). Docente do Colégio Pedro II. E-mail: alexandre.historiadaarte@gmail.com. ORCID: https://orcid.org/00000003-1681-3295. Lattes iD: http://lattes.cnpq.br/9358213563291663. Rio de Janeiro, Brasil. 


\section{Da selva originária, da ferida primária}

Nem mesmo a pandemia tornou a governança e os poderes políticos constituídos mais conscientes ou sensíveis aos sinais de alerta. A incontinência na sociedade do capitalismo avançado segue arriscando o âmago da vida e trazendo o desastre, carregando, no entanto, atrás de si, planos de emergência e alerta global. Alertas globais já anunciavam a crise humanitária e ambiental na ruína do mundo, clamores que antecedem a própria era das máquinas e os ruídos das fábricas - no caso brasileiro e especificamente no cenário carioca -, um abismo climático que remonta à colonização, quando as florestas de Pau-Brasil foram dizimadas, os povos indígenas exterminados ou escravizados: um rastro de destruição que marcou esse encontro, configurando o que podemos definir como nossa ferida primária.

Apesar de vivermos uma época em que Ailton Krenak nos oferece "Ideias para adiar o fim do Mundo" (2019), acompanhado de discursos preocupados com os rumos do planeta, seguimos também essas vozes no cenário internacional: conforme também observa Bruno Latour (2020) em suas conferências e reflexões, evocando a mitologia de Gaia e chamando atenção sobre as catástrofes advindas do Antropoceno, assistimos, sem trégua, a destruição que se repete todos os dias.

A coisa não para, toda manhã começa tudo de novo. Um dia é o aumento do nível da água; o outro, a erosão do solo; à noite, o derretimento acelerado das geleiras. No jornal das oito, entre dois relatos de crimes de guerra, somos informados de que milhares de espécies estão prestes a desaparecer antes mesmo de terem sido devidamente identificadas. (LATOUR, 2020, p.23)

Apesar de intensos protestos, onde até mesmo as crianças se fazem representar para reclamar pelos seus direitos ao futuro (na figura de Greta Thunberg), os governos não agem de forma efetiva para conter e reverter o sistema de destruição e a maior parte da população mundial parece estar alheia, negando-se a debater e agir sobre o problema; as atitudes são tomadas de forma cínica e alienada. Seguimos em direção ao desastre.

Não obstante, na contramão deste descaso, muitos discursos - científicos, políticos, artísticos - vêm se pronunciando em defesa de um futuro possível. Assim, sensibilizados com este tema, gerador de tantas angústias, o presente texto, de modo a ampliar este debate, visa discutir justamente as contribuições estéticas e ações performativas que vêm ocupando diversos contextos e realidades, alterando o panorama nas cidades. São como estratégias de reverberação da natureza nos centros econômicos e políticos, ambientes de alta concentração demográfica. Se tornando, assim, fronteiras críticas simbólicas e geográficas nestes territórios urbanos. 
Um dos objetivos é fazer ecoar as questões que se relacionam aos clamores contra o que o nosso planeta vem sofrendo, por meio de diversas linguagens e procedências imagéticas, um modo de escuta às vozes daqueles que agem por uma revolução cognitiva, habitando um mundo que precisa urgentemente renascer. Em programas artísticos constituídos e conectados com o ambiente natural, se opondo aos imperativos do "progresso" e, neste sentido, substituindo o que convencionou se chamar de "desenvolvimento" pelas práticas de envolvimento, integrando-se às diversas manifestações de vida ou às múltiplas formas expressivas que dialogam com natureza e as questões ambientais do planeta. Assim, sensibilizados com este tema gerador, motivos de tantas preocupações, discutimos as perturbações estéticas que vêm ocupando diversos contextos em nossa cidade, o Rio de Janeiro, agentes críticos atuantes nas fronteiras simbólicas e geográficas destes territórios.

Atenta-se que diversas expedições artísticas e científicas estiveram no Brasil e que chegaram ao Rio de Janeiro, onde o diverso grupo chamado genericamente de viajantes, deixou impressa as marcas de empreendimentos de documentação e de aventuras românticas, na busca de novos ares nos trópicos, dando outro rumo às suas respectivas carreiras, cumprindo-se o intuito de produzir um grande inventário visual da natureza. Autores, portanto, de uma vasta iconografia representativa do "Novo Mundo" - conceito cunhado à época da colonização, porém inaceitável sob o ponto de vista dos povos originários.

Além da Missão Artística Francesa que desembarcara no Rio de Janeiro em 1816, tivemos a presença de austríacos, que integraram a comitiva da princesa Leopoldina em 1817, bem como de alemães, holandeses, ingleses, que chegaram em muitas levas, cumprindo o que pode ser lido como uma nova agenda [re]colonizadora, protagonizada e impulsionada por imagens. Um ambiente de corte se forma e exigia uma moldura cultural apropriada, tanto artística quanto científica. Os "pintores de paisagem, animais e coisas extraordinárias" eram admitidos na instauração de um cenário ilustrado quando o Brasil tornou-se sede do Reino de Portugal (LEVY et Al, 1994).

Todo o território da América Latina foi transitado por artistas, naturalistas e botânicos de várias nacionalidades europeias que, em busca de fama e reconhecimento, atenderam, sobretudo, aos empreendimentos civilizatórios, científicos e colonizadores. Parte deste acervo, até hoje, ainda permanece distante dos olhares dos brasileiros, confinados em instituições europeias.

Nicolas Antonie Taunay (1755-1830), Thomas Ender (1783-1875), Johann Moritz Rugendas (1802-1858) são artistas que nos oferecem muitas pistas 
sobre a relação mantida entre este tipo de arte diante da natureza. Vale lembrar que as temáticas e muitos interesses foram substituídos, porém, não alienando-se do olhar colonizador. A separação entre natureza e cultura são evidentes em todas estas obras. Na obra "Mata Virgem perto de Mangaratiba" de Rugendas (imagem 1), por exemplo, encontramos o fascínio deste artista pela Mata Atlântica, enquadrando-se a natureza em uma janela, ativando os argumentos vinculados à invenção da paisagem (CAUQUELIN, 2007). Ademais, deve-se observar que as paisagens criadas neste período pelos viajantes estão classificadas sob uma visão pitoresca, ordenadas pelo olhar que se confunde com o interesse científico de catalogação das espécies, além de ser governado pelos cânones de representação próprio da formação acadêmica destes artistas. Assim, dados civilizatórios se prendem à própria linguagem da pintura, também denunciados pela iconografia apresentada, emoldurada nos limites das obras que, por sua vez, se constituem muito mais sobre o olhar distanciado da natureza dos europeus, do que propriamente de uma visão que a compreenda plenamente.

Por outro lado, percebemos que estão sensíveis aos peculiares traços locais que pouco a pouco vão - em maior ou menor medida -, aprendendo a considerar em detalhes e a representar, reconhecendo não apenas uma

Figura 1 Johann Moritz Rugendas. Mata Virgem perto de Mangaratiba província do Rio de Janeiro, 1835. Gravura, $34 \times 50,5 \mathrm{~cm}$. Fonte: Enciclopédia Itaú Cultural de Arte e Cultura Brasileiras

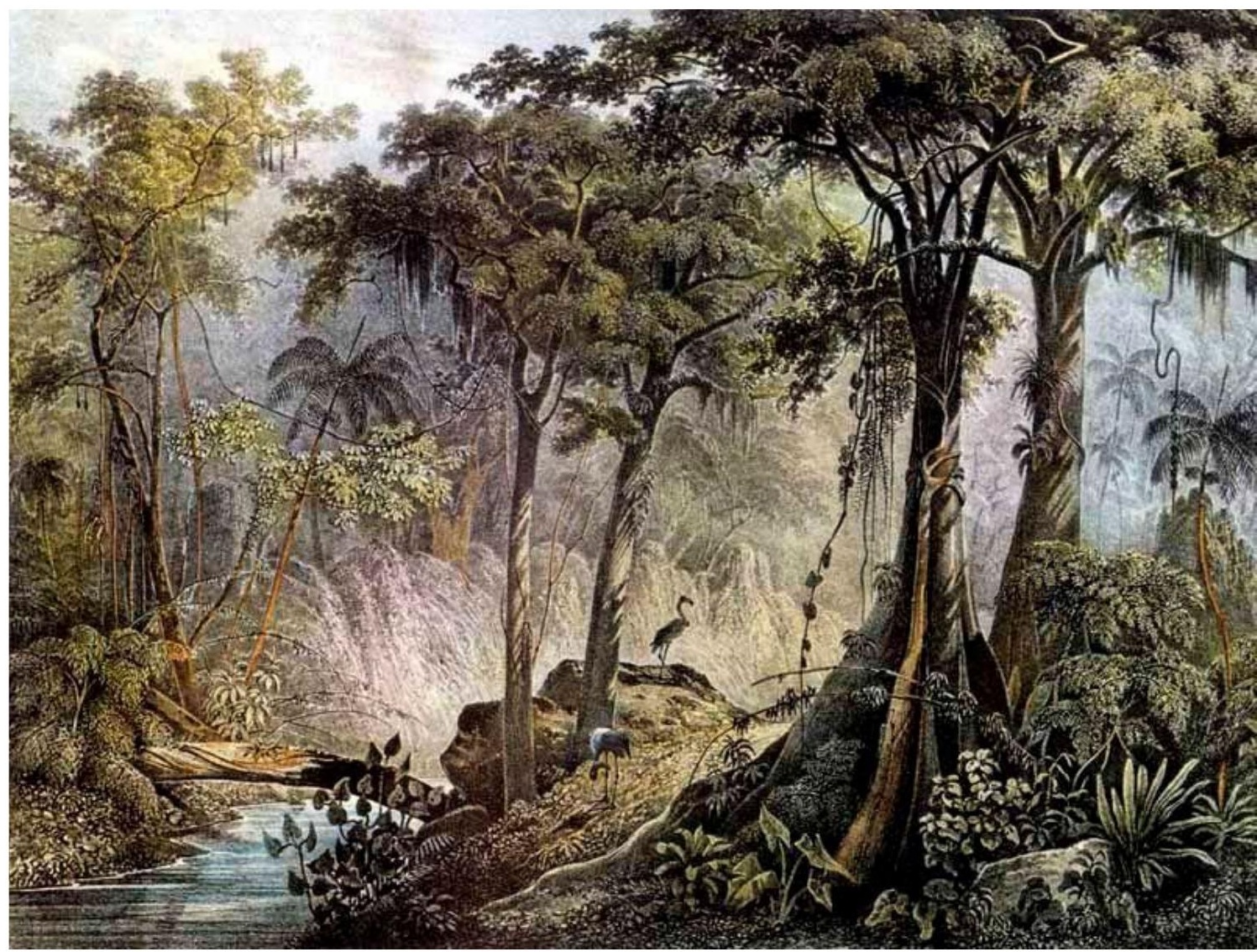


natureza, mas múltiplas naturezas, dado as dimensões extensas e as formas de suas configurações.

As florestas nativas constituem a parte mais interessante das paisagens do Brasil, mas também a menos suscetível de descrição. Em vão procuraria um artista um posto de observação nessas florestas em que o olhar penetra além de poucos passos, as leis de sua arte não lhe permitem exprimir com inteira fidelidade as variedades inumeráveis das formas e das cores ... (RUGENDAS Apud LEVY et Al, 1994: 34).

Johann Moritz Rugendas (Augsburg, Alemanha 1802 - Weilheim, Alemanha 1858), ao desembarcar no Brasil em 1821, na condição de artista da expedição chefiada pelo barão e médico Georg Heinrich von Langsdorff, estava acompanhado de um grupo que reunia cerca de quarenta pessoas entre artistas, astrônomos, botânicos e naturalistas. Era bastante jovem quando chegou nestas terras, tendo, à época, pouco mais de 20 anos, certamente ávido pela busca de reconhecimento em um período de grande concorrência, onde a produção de imagens nos trópicos era intensa. Atravessado pelo viés romântico, cujas as bases trazia da Alemanha e de sua formação na Academia de Belas Artes de Munique, Rugendas esteve em inúmeras regiões e províncias brasileiras (Rio de Janeiro, São Paulo, Bahia, Minas Gerais, Mato

Figura 2

Johann Moritz Rugendas. Derrubada

de uma Floresta

(Defrichement d'une

Forêt), 1822- 1825.

Litografia sobre papel,

$21,60 \mathrm{~cm} \times 28,50 \mathrm{~cm}$.

Fonte: Enciclopédia

Itaú Cultural de Arte

e Cultura Brasileiras

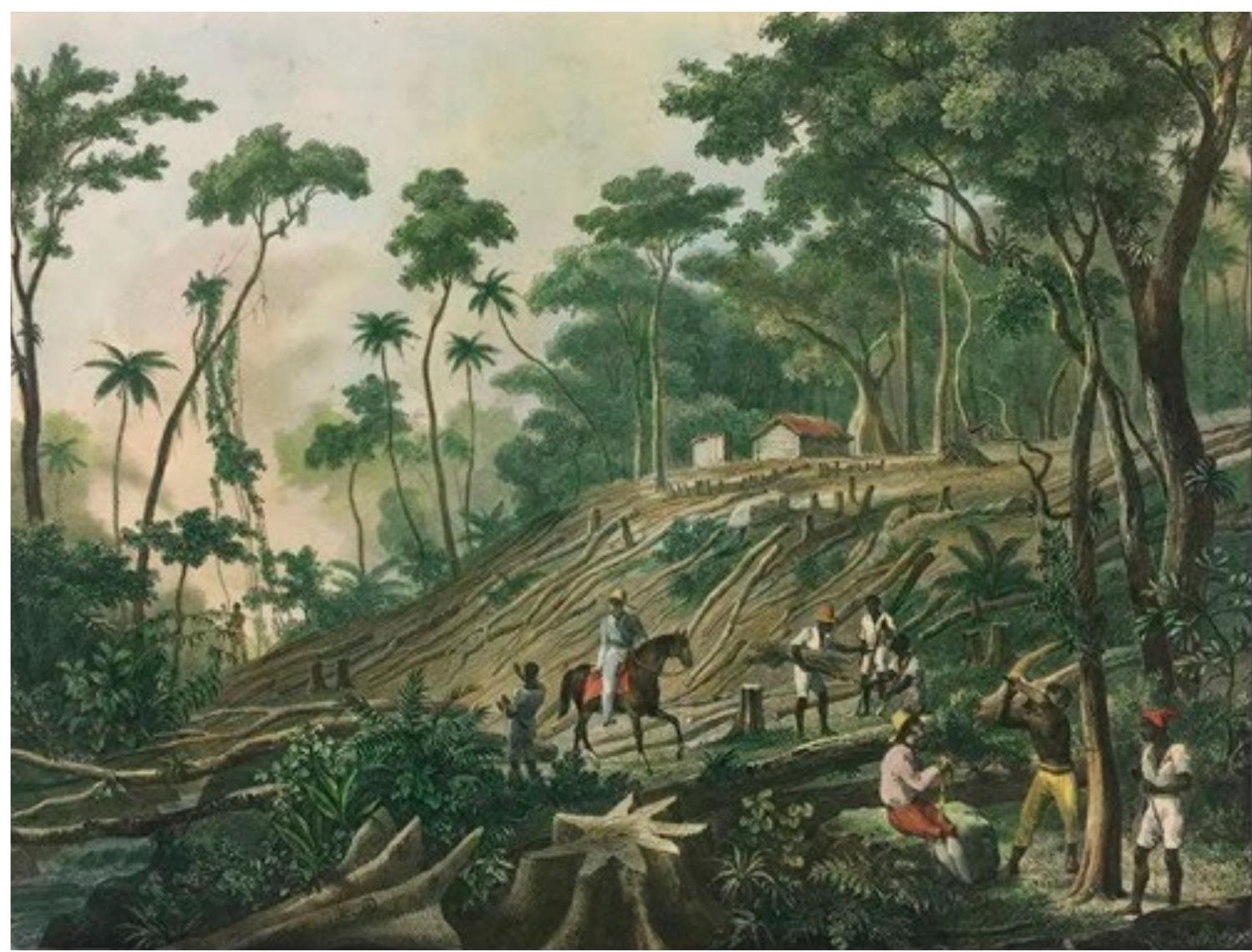


Grosso, Espírito Santo), encontrado e registrando uma natureza ainda selvagem, mas também se defrontando com a mata sendo devastada pela ação de fazendeiros, como na obra "Derrubada de uma floresta" (1822-1825), denunciando uma prática predatória no Rio de Janeiro e de outras áreas do sudeste brasileiro para o plantio e o cultivo do café.

Distantes dos primeiros quadros de representação do "Novo Mundo", com animais esdrúxulos e seres grotescos das gravuras que circulavam no século XVI, esses artistas, já impregnados pela razão iluminista e descortinando o apreço romântico pela paisagem, vão trazer, para os trópicos, um encantamento com a beleza natural que ainda não existia aqui. É derivada dessa apreciação que podemos indagar se não devemos a ela a existência da atual Floresta da Tijuca, recuperada em 1861 a mando do neto de D. João VI, D. Pedro II.

A temática da natureza foi evocada diversas vezes por diferentes períodos históricos, a envolver diversas realidades, porém, nem sempre se reivindicando um espaço discursivo de proteção ou gerador de consciência maior sobre a biodiversidade. É usual ouvir, das populações não tocadas pelo apreço à natureza, o termo "animal" para se referir a toda e qualquer criatura não humana colocada nessa categoria inexpressiva e indiferente. Não apenas no passado, mas ainda hoje a realidade do estatuto desprezível se constata: planta ou animal, mato ou bicho, denominações genéricas para servir ao pensamento utilitarista com relação à natureza resistem nestes 500 anos de domínio cognitivo eurocêntrico colonialista. Ressalta-se que no caso das obras dos artistas viajantes, em articulação com o pensamento de Ailton Krenak (Op. cit.), subsiste a "(...) ideia de que os brancos europeus podiam sair colonizando o resto do mundo", amparado no entendimento hierarquizado de espírito conquistador de "(...) uma humanidade esclarecida que precisava ir ao encontro da humanidade obscurecida, trazendo-a para essa luz incrível." (Op cit. p.11).

A corte real, no entanto, irá inaugurar o desfrute junto ao mundo natural. O gosto pela paisagem e pelo passeio na mata, as corridas de cavalo, os banhos de mar foram hábitos desta corte portuguesa que se enraizaram. A sensibilidade cultivada pelos aportes paisagísticos, entendemos, é educada pelos pintores naturalistas e românticos que estiveram aqui, trazidos por demandas internas ou externas e, mais tarde, influenciando e formando artistas nacionais.

Acrescenta-se, acerca destes hábitos europeus difundidos nos trópicos que, mesmo com "(...) o controle artificial da natureza" (CARVALHO, 1999, p. 17) se estendendo à cidade pelo avanço da prática iluminista, com a 
inauguração do Passeio Público em 1785, não se desfaz o interesse pelo passeio nas matas. Assim, a ideia de jardins a serviço de uma aristocracia local no perímetro urbano histórico de Rio de Janeiro não é suficiente para explicar as múltiplas relações entre a sociedade e natureza forjadas à época.

Antoine Taunay não chegou ao Brasil exatamente como um viajante, mas como pintor da corte e professor. Chegou ao Rio de Janeiro como membro da Missão Francesa a convite da corte de D. João VI, em 1816 e, pelo

Figura 3

Antoine Taunay. Cascatinha da Floresta da Tijuca, 18161821. Fonte: Wikimedia Commons

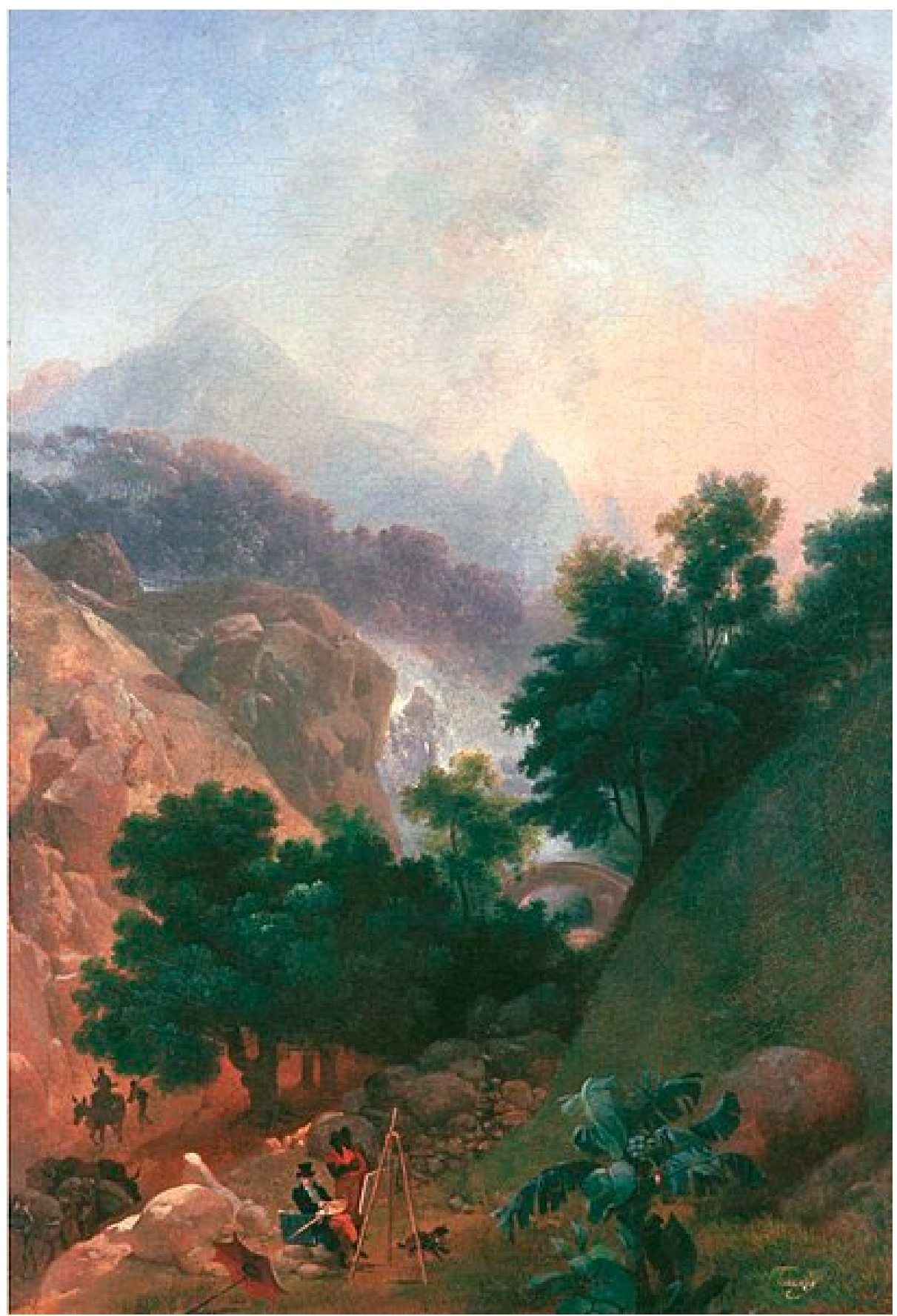


pouco tempo que aqui passou e pelas paisagens bucólicas que buscou junto à Mata Atlântica, Taunay é um dos artistas que devemos relembrar por ter registrado preciosos pontos paisagísticos que se tornaram locais de frequentação. Pintor de paisagem, encantou-se com as localidades na Floresta da Tijuca e revelou um de seus encantos, a Cascatinha (imagem 3 ). Ainda que não tenha sido reconhecida sua contribuição à arte brasileira como algo inovador, desprendido do olhar europeu e pelo pouco tempo que aqui permaneceu (1816-1821), a pintura nos mostra o apreço pelo passeio na mata, o aprazível encontro cultivado em uma aproximação com a floresta que circunda a cidade e cujo desejo de desfrute herdamos da corte real e que se mantém até os dias atuais. Entre nós, cariocas, podemos indicar o movimento de cuidado às nossas matas desde os séculos XVIII, quando foram recuperadas em nossa cidade, no replantio da Mata Atlântica. Buscando salvar as fontes de água que abasteciam toda a população e que haviam sido gravemente prejudicadas pelo desmatamento progressivo no cultivo de café ao redor de suas montanhas, por ordem imperial, criou-se a nossa peculiar Floresta da Tijuca.

Na pintura "Vista de um mato virgem que está reduzindo à carvão" [c.1845], de autoria de Félix-Émile Taunay (França 1795 - Brasil, 1881), dando outro encaminhamento à obra do pai, se distanciando de uma concepção de um "arcadismo pastoril" (SCHWARCZ, 2008, p. 247), encontramos o registro visual de uma floresta que já pedia socorro. Nesta obra, a denúncia do "(...) corte de madeira e a sua transformação em carvão" (Op. cit, p.247). Segundo a visão do próprio artista, o prenúncio catastrófico das alterações climáticas na cidade que se seguirão no tempo futuro.

Meio século depois, o Grupo Grimm recuperava um outro aporte à natureza, a do espaço da floresta como não mais impenetrável. Saíam de sua borda, das vias e estradas reais e mergulhavam nas matas (CAMPOFIORITO, 1983). Entendemos que seu fundador, Georg Grimm, pode ser considerado um tardio pintor viajante: depois de viagens à Itália, Turquia, Grécia e Palestina, chega ao Brasil em 1878, onde esteve como presença marcante. Fixando-se no Rio de Janeiro mas continuamente em deslocamento, exercitando-se no papel de desbravador, "internando-se mato adentro" (p. 212), compôs inúmeras pinturas sobre a paisagem do Sudeste Brasileiro. Professor dissidente da Escola de Belas Artes, gerou um movimento próprio, que iria afirmar esse amor ao encontro com o ambiente natural: "Fazia-se acompanhar pelos jovens aos pontos mais penosos, de onde passavam a executar os trechos que preferiam da paisagem."(Op. cit.). O prazer de estar ao ar livre, a valorização dos cenários de fronteira entre a floresta e a cidade, deixaram marcas profundas no olhar de seus contemporâneos e, especialmente, de seus 
Figura 4

Félix-Émile Taunay. Mata Reduzida a Carvão, 1830. Fonte: Enciclopédia Itaú Cultural de Arte e Cultura Brasileiras

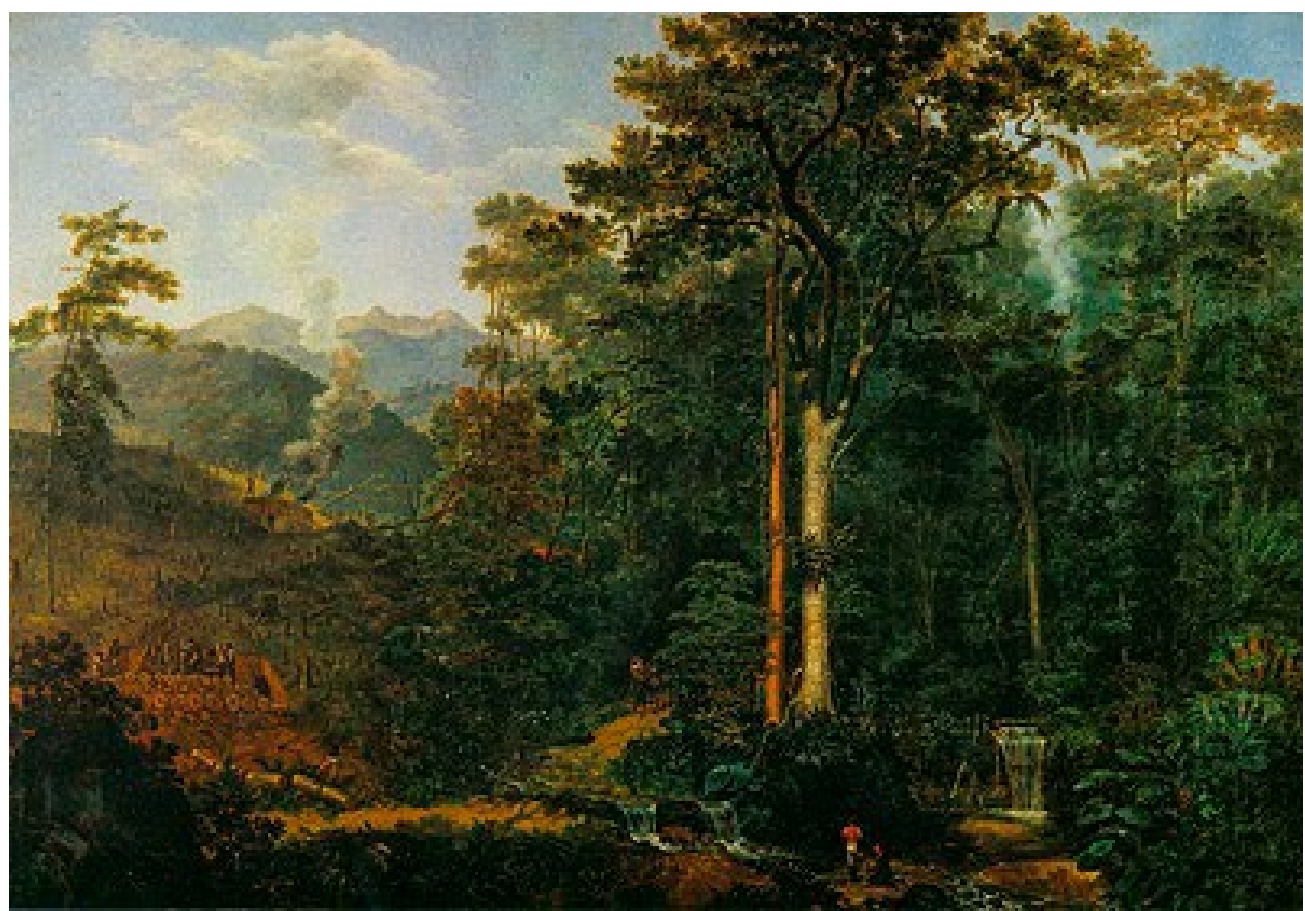

jovens aprendizes, dentre eles futuros grandes paisagistas como Antônio Parreiras e Giovanni Castagneto, que afirmaram o gênero e aprimoraram o gosto pela arte mais sutil no encontro entre a natureza e a cultura.

\section{O tempo em naturezas da arte}

Infelizmente, desde o século XX, os governantes no Rio de Janeiro não têm manifestado interesse para o cuidado com as áreas verdes do entorno. Com a rápida modernização do país, a cidade recebeu inúmeras levas de imigrantes, e muitos se alocaram nos morros, em zonas de floresta, conformando grandes conglomerados urbanos, em ocupações irregulares, mas as únicas possíveis em situação de precariedade, as favelas. Hoje, a situação é muito grave: vemos crescimento exponencial em um ilícito mercado imobiliário com ameaças em construções por grandes extensões de mata e de mangue.

A pressão imobiliária nas zonas de floresta é constante. É uma visão calcada na engenharia habitacional e rodoviária que tem sido o motor de nossa frágil economia; à qual, somada ao turismo que decai sensivelmente, servem de plataforma eleitoral e deflagram planos de desenvolvimento onde a natureza e a força da mão de obra barata são a base principal de exploração.

Contrariamente aos interesses dos dirigentes, grupos de ativistas se mobilizam para a defesa do patrimônio verde da cidade e geram movimentos de 
alerta e educação ambiental. Dentre esses esforços, podemos observar a arte intervindo de modo contundente. É a esse engajamento que nos debruçamos ao notar que geram não exatamente um vínculo com os ambientalistas, mas que produzem um núcleo novo de reflexividades que enriquecem o campo artístico, propondo novos modos de presença e estados perceptivos diferenciados, zonas sensoriais alteradas promovendo a relação humana com o meio natural e, podemos dizer, assim, produzindo outras concepções de natureza, recriando o próprio sentido do que seja o natural; Assim como em outras cosmogonias, a imersão poética segue abrindo espaço para estarmos convivendo com o plural - essa diversidade exuberante de espécies e forças e, mais além, produzindo naturezas diversas.

Figura 5

Luiz Zerbini. Campo Expandido (detalhe), 2020 . Zona imersiva criada para Exposição no Centro Cultural Oi Futuro, 2020. Foto Pat Kilgore. Imagem gentilmente cedida pelo artista e pelo fotógrafo

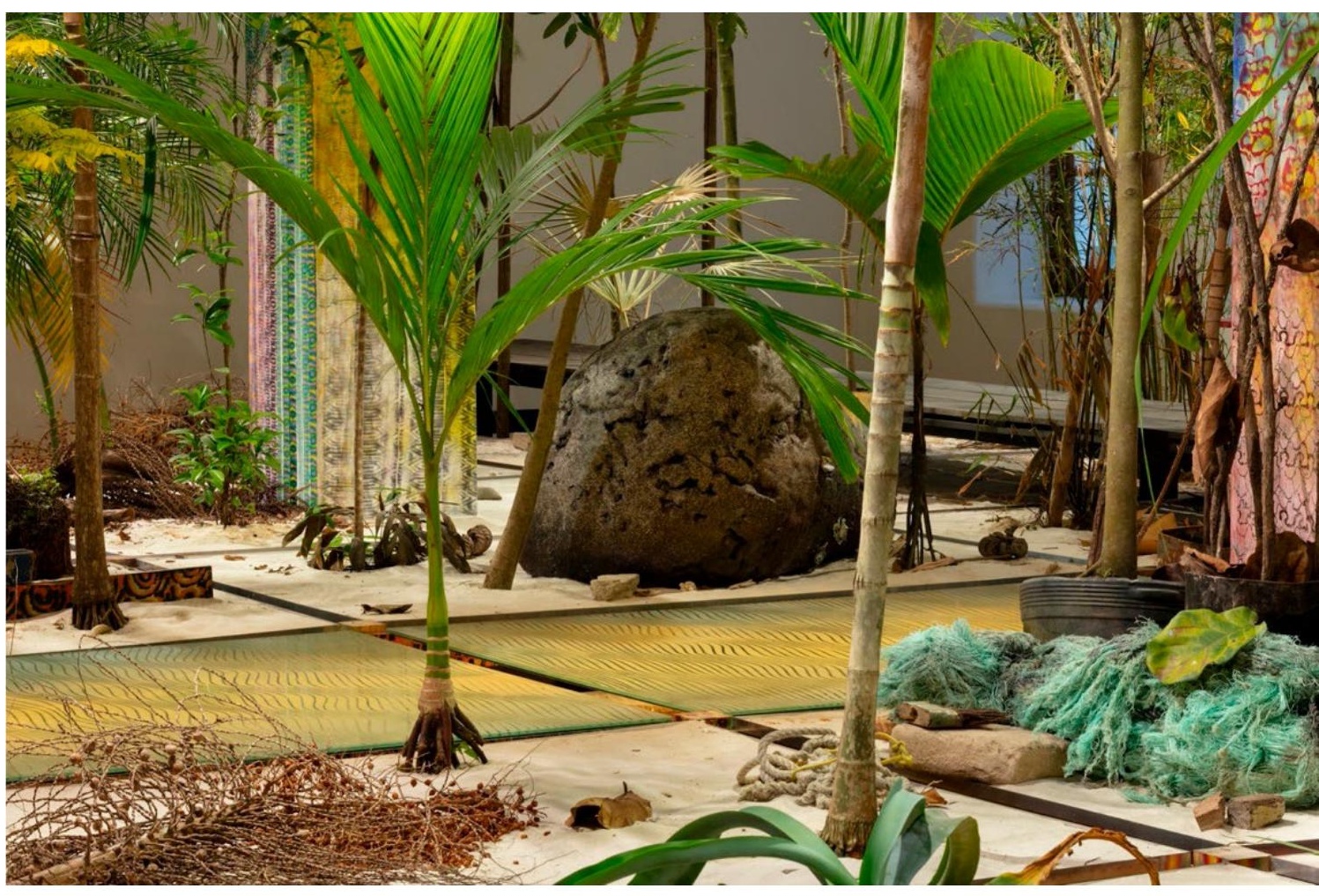

Na obra Campo Expandido, espaço em recriação da natureza silvestre pelo artista carioca Luiz Zerbini, percebemos uma primeira ordem que se estabelece pelos planos da base em pranchas de madeira, mas que se ergue em livre composição, os elementos colocados em diálogo, gerando um aspecto visual profuso. Uma obra marcada pelo tempo de vida desses seres e coisas, onde alguns objetos se desfazem, entrópicos, e as plantas podem começar o seu trabalho derivante, um jogo de riquezas demiúrgicas - diálogo entre o artista e a natureza - em texturas, cromas, linhas, formas, aromas. Zerbini 
define essa instalação como um "jardim japonês tropical”, tema recorrente em algumas de suas obras que revisita: "Ele é natureza, é espiritual, é a natureza espiritual da realidade" diz o artista, ao definir a própria natureza da arte, em um jogo fecundo de remetentes.

Ao invés de nos levar ao mundo florestal, ele recria a natureza no ambiente artístico, transformando o cubo branco das galerias e de todo o cenário interno no Centro Cultural Oi Futuro. Nesse âmbito, o artista explicita que se trata de uma pintura extrapolada para um além da pintura, se fazendo como instalação imersiva que absorve todos os elementos anteriormente utilizados. Ele se torna, assim, pelo próprio percurso à uma pintura expandida, nosso veículo de passagem da pintura oitocentista para a arte contemporânea, nos permitindo saborear todos os deleites antevistos por seus antecessores na agência política da imagem, na criação de um elo do passado pré-moderno, sem ruptura em todo esse percurso da arte da paisagem, mas que acontece em uma outra ordem, a de encantamento.

Zerbini nos leva a transitar por uma dimensão da imagem onde subsiste uma zona central constituída por um gesto curador, nele habita o artista/xamã. Na performance de um corpo que emula a paisagem com uma espécie de turíbulo - defumador ou fumigador? - Há uma indiferenciação neste gesto, pois as vestes do artista performer se fazem como a de um apicultor ou fumigador, e ele caminha gerando uma névoa que adensa a atmosfera; algo se vela mas outros vieses se abrem, os véus de fumaça introduzindo novas camadas existenciais e revelando aspectos do que estaria anteriormente invisibilizado. Penumbras coloridas, sombras das luzes inebriantes, psicodélicas, emitidas por spots em cores primárias que atravessam todo o percurso pelo ambiente e vão, paulatinamente, na medida em nos impregnam o olhar, nos deixando mais afetados por esses seres, as plantas, que se misturam uns com os outros e, ainda, rebatem sobre a névoa esfumaçada, perfazendo raios e brumas que se espalham, vibram e nos capturam. A obra nos lembra que cada um desses seres se exprime como mônadas, cápsulas reguladoras, fontes emissoras de gases e luzes imperceptíveis aos nossos aparelhos sensoriais mas que juntas, geram uma atmosfera, um halo envolvente. Em um certo momento, mãos emergem, desafogando-se paulatinamente de uma camada de luz vermelha, o artista caminha e aparece medonho, com seu capuz de apicultor, um ser extra mundos ou, na verdade, intra mundos. Somos capturados pelo seu feitiço: o turvamento do olhar nos equipara ao ininteligível estado mental do transe, na suspensão da racionalidade ordinária e previsível. 
Em nossa perspectiva, o jardim japonês, ao qual se remete o artista, se aclimatou e perdeu a pureza: Na imersão é selvagem, ambíguo como uma borda de floresta urbana, contendo despojos, algo de lixo e de descarte. Nessa bruma indistinta o entendimento se esvai, a razão não se sustenta. Múltiplas camadas se erguem e se enlaçam em miríades de conformações inusitadas, todas relativas às vidas dos seres que estão ali se desenvolvendo, em seus nichos próprios, espécimes reproduzindo um modelo genético mas em singular situação, uma particular existência que vibra em contexto. Cada pedaço dele nos apresenta o desafio de uma espécie em sua [des]ordem.

Byu-Chul-Han (2021) sustenta a tese hegeliana sobre a lógica conclusiva da razão: "todo racional é um silogismo" (p.51). Controlada pelo olhar analítico, a razão é advinda da discriminação de cada elemento em unidades, lógica dos elementos separados em uma grade, nichos alocadores em fragmentos, distribuídos, separadamente, a cada lugar próprio do entendimento analítico e, por operações causais, dedutivas, chegam a um único estamento, conclusivo. No Campo Expandido a lógica não pode subsistir, dando lugar ao encantamento.

Seguindo um outro viés, por essa peculiar expressão da vida, a artista Lia do Rio se desvela em processos imersivos próprios, criando em diálogo com a própria Mata Atlântica. Entre seus inúmeros trabalhos, recolhendo folhas, sementes, criando clareiras ou reunindo e aglutinando os materiais neste meio/floresta, Lia remete à uma ultrapassagem do tempo ordinário, escapando dos grilhões do sentido em flecha para produzir a experiência da realidade atemporal na obra "o tempo não para". Ao redor de uma esplêndida árvore centenária, esculpe uma frase em cimento que, ao ser lida, nos leva a seguir indefinidamente, circundando-a, na expressão vivenciada de um tempo que sempre retorna, refazendo-se a cada giro.

Para seguirmos Lia, temos que adentrar bem no núcleo da floresta, lá onde habitam esses seres imensos, hoje raros, que são as árvores matriciais. Muito provavelmente, essa árvore é uma das remanescentes da mata originária, dado o seu tamanho, testemunha de toda a história que contamos aqui sobre a Floresta da Tijuca. Estaria já no local antes mesmo da mata ser destruída, tendo sobrevivido à sanha extrativista e cafeicultora. Pois Lia nos faz seguir até ela, encontrar essa criatura em permanente estado de verticalidade, em crescimento contínuo, no que podemos apreender como um dos eixos da terra. No tronco/eixo, ao girarmos, contemplamos o que está para sempre se alternando, mas, ao mesmo tempo, se mantendo, crescendo como tudo na própria na natureza para seguir permanecendo viva. 


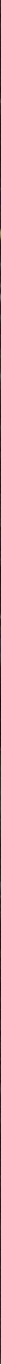

Figura 6

Lia do Rio. Aion, 1998.

Foto Lia do Rio. Imagem gentilmente cedida pelo artista
Inconformada, Lia cimentou em volta de uma árvore, lenta em seu crescer, afirmou: "O tempo não passa". Porque empilhadas sobre a natureza do hábito, passam essas palavras de cimento, melifluamente, da coisa da afirmação para a da interrogação: O tempo passa? Passa? Passa com velocidade? Não é ele, por acaso, o denominador comum de todas as velocidades? Aristóteles talvez tivesse razão: o que há são mudanças. O tempo, na verdade, é um modo de diferenciá-las e quantificá-las em sua vertiginosa diversidade. (LYRA, 2014:71)

A obra de Lia do Rio ...otemponãopara... nos torna visitantes/viajantes, sujeitos que se deslocam dentro da floresta para filosofar. Tornada monumento, paradoxalmente, a árvore centenária mantém-se, atávica, e segue a reproduzir a contínua linha de sua espécie (DO RIO, 2014).

A mostra "Para o silêncio das plantas" de João Modé, por sua vez, nos leva à floresta de outro modo: vamos para nos comunicar com as plantas, para tocar para elas, para estar com elas. Ocupando a galeria externa no Parque Lage, as Cavalariças, espaço de tangenciamento da Mata Atlântica, Modé conduz o público por duas linhas mestras: uma, a corda que, desde o portão de entrada do parque, desce do alto e penetra na galeria seguindo em direção à mata e a outra, uma plataforma, que ziguezagueia pelo chão, sendo o caminho que nos descortina ludicamente modos de imersão no verde, 
como um "caminho da roça"; cada um seguindo seu próprio andar, isolado pelos limites estreitos do estrado. Algumas escolhas são obrigatórias, pois o caminho se bifurca e gera novos percursos; porém, todos encontram seu próprio limite, neles cada andarilho deve retornar, sozinho, por onde haverá passado. Jogo dos contrários sem sentido, puro estar presente e retomar por sobre experiências vividas: voltar o passo é olhar também o mesmo de outro modo, encontrando-se a si mesmo em direção oposta.

Algumas trilhas chegam em lugares de se estar parado, de sentir aromas ou de tocar música - alguns instrumentos haviam sido dispostos anteriormente, na sala de partida, para que se pudesse fazer sonoridades, em ritmo ou melodia. Referendadas em pesquisas científicas sobre sonoridades como meio de interação com o mundo botânico, experiências que o artista absorve nesse interlúdio poético entre seres de reinos diferentes - humanos e plantas tropicais.

Figura 7

João Modé. Para o silêncio das plantas (detalhe), 2011. A obra penetra na borda da Mata Atlântica ao redor do Parque Lage. Foto Wilton Montenegro. Imagem gentilmente cedida por artista e fotógrafo. Fonte: Catálogo da exposição Para o silêncio das plantas nas Cavalariças, EAV/ Parque Lage, RJ, 2012

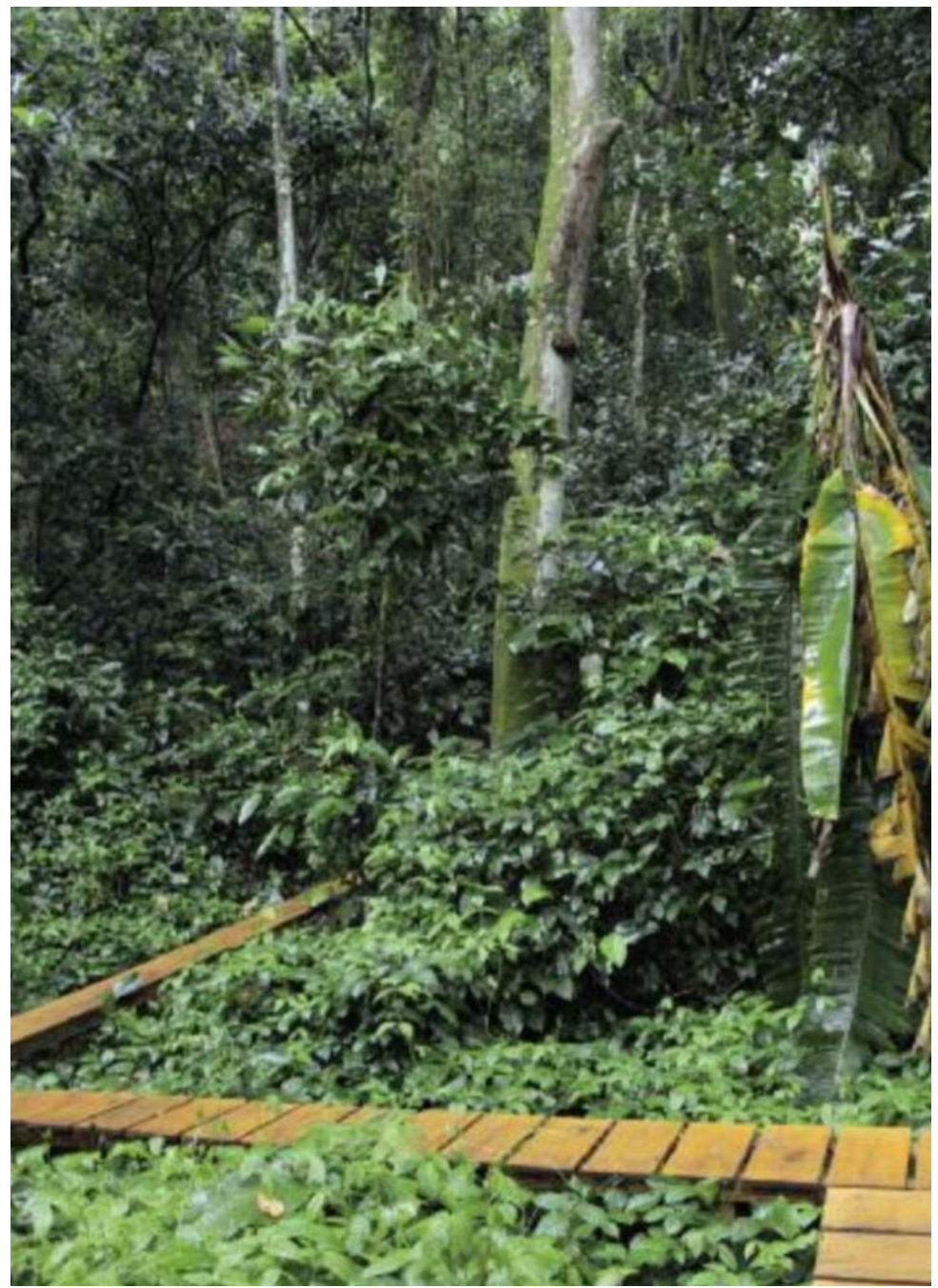


Considera-se importante tratar ainda da relação entre natureza e as questões trazidas à tona por artistas da favela, onde podemos encontrar questões fundamentais sobre relação arte e meio ambiente. Após muitas subidas e descidas pelos morros cariocas, se embrenhando nas iconografias dos viajantes e nas instalações dos contemporâneos, é importante redirecionar nosso olhar para a Revolução Artística do Morrinho, situada na favela da Pereira da Silva, na Zona Sul da capital carioca. Observa-se nesta poética coletiva, instalada em uma favela diferente das outras (ROCHA, 2013), a relação de amizade e diálogo permanente com a floresta, com contribuições sensivelmente particulares à presente reflexão. No Morrinho, em suas inúmeras narrativas e vertentes associadas às favelas cariocas, uma discursividade que se mantém tão viva quanto a densa mata que a envolve, junto a APA (Área de Proteção Ambiental) do bairro de Laranjeiras, promovendo ações e discursos de sustentabilidade na sua relação fértil de compreensão à biodiversidade que a abraça. O próprio termo favela oferece esta perspectiva híbrida, processual e viva das naturezas-culturas (DESCOLA, 2016), estando associada tanto à planta típica do sertão brasileiro - signo de resistência do semiárido que desafia o regime das secas -, além de se relacionar à outra acepção - mais comum entre os cariocas -, das construções também de muitas resistências que se aliam à natureza e ao desenho dos morros, outrora representado pelos viajantes.

Assim, em muitos sentidos, considerando não apenas a questão linguística de dupla conotação do termo favela, mas o contexto particular desta manifestação artística, envolvendo a participação de muitos jovens da comunidade

Figura 8

Projeto Morrinho. Registro da instalação na favela Pereira da Silva - Rio de Janeiro, 2016. Foto Alexandre Guimarães. Fonte: Arquivo do pesquisador Alexandre Guimarães

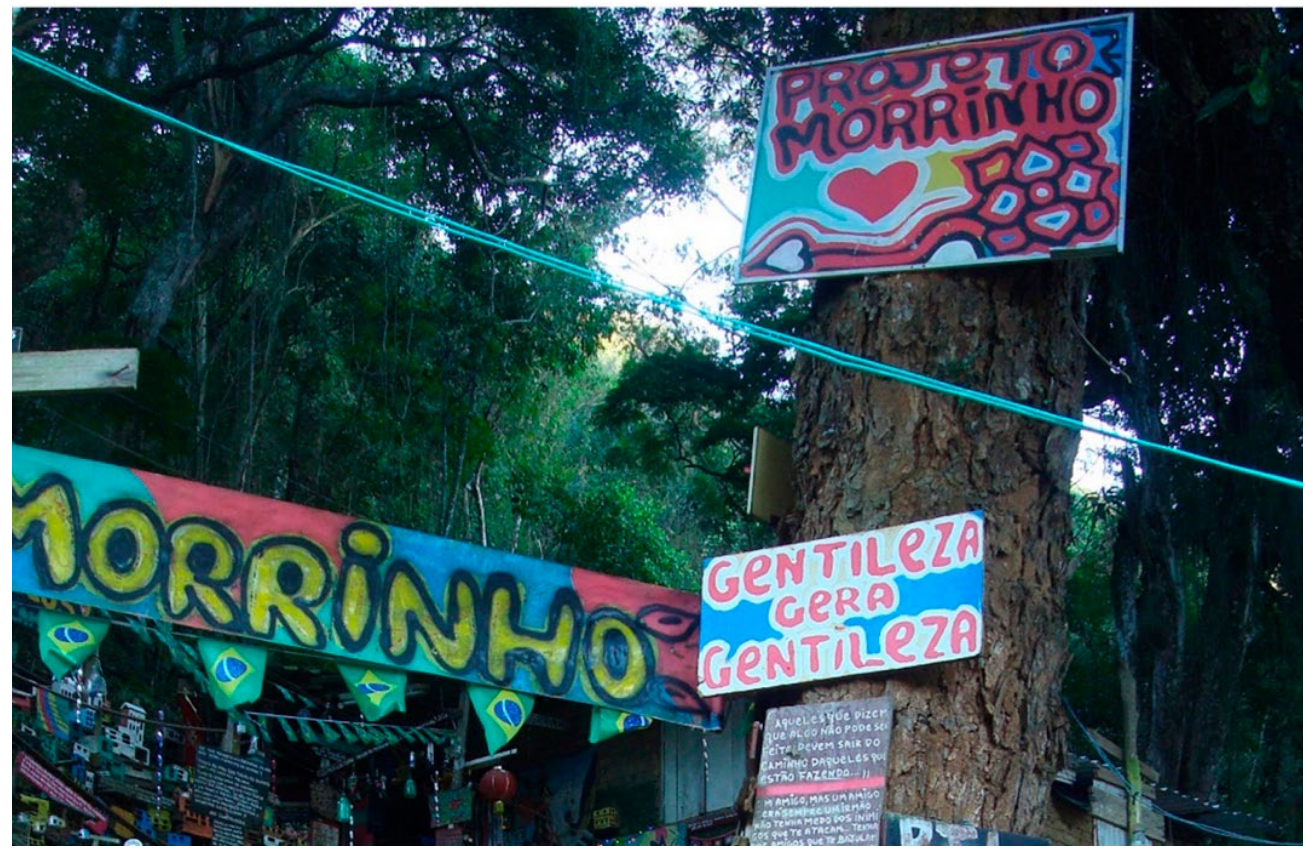


do Pereirão, a verificação de seus aspectos híbridos de não-separabilidade entre natureza e cultura (LATOUR, 2013). O Morrinho, assim, não parece ser um fenômeno, enfim, que possa ser bem compreendido/traduzido de modo assimétrico. Na favela Pereira da Silva, onde se mantém viva boa parte das suas narrativas há mais de duas décadas, é importante observar, não há ação que não se misture à terra, que negue ou se comporte indiferente às transformações cíclicas provocadas pelas estações do ano que, se revezam em meio a sons e ruídos, temperaturas e sensações térmicas, sinais e prodígios da floresta que envolvem esta realidade, assentada em área de proteção ambiental na Zona Sul do Rio de Janeiro. Está envolta, integrada e protegida, portanto, por um campo extenso de acontecimentos, onde coabitam e convivem, indistintamente, inúmeras espécies de eventos sociais e naturais. Assim, na companhia de imponentes jaqueiras e mangueiras, por exemplo, este pequeno mundo brincante que se anuncia e se ergue a cada dia de modo distinto, conjuga-se à beleza de uma exuberância híbrida, difícil de ser superada. Aqui a palheta também se encontra em movência, multiplicada pelo trânsito intenso com a natureza. Descortina-se em meio a vegetação local, portanto, um "teatro" de transformações permanentes a céu aberto, oferecendo aos seus visitantes, múltiplas narrativas de seus desdobramentos (INGOLD, 2015, p. 248). Nesta rica articulação, não se percebe a natureza na condição de "estrangeira" (LATOUR, Op. cit., p.36).

Importante ressaltar que é longa a relação entre o Morrinho de respeito à natureza, se confundindo, inclusive, com as primeiras memórias desta obra, sempre em transformação. Segundo um de seus criadores e membro fundador do Projeto Morrinho, Cirlan Oliveira, a primeira pessoa "de fora" que chegou para conhecer o Morrinho foi seu professor de Meio Ambiente Rodrigo, do Projeto "Vida Nova". Também conhecido como "Quico", dava aulas para boa parte dos adolescentes da comunidade que também brincavam na maquete. Depois de conhecer a grande obra, pôde compreender melhor o que estava acontecendo no Pereirão, constatando que tudo que estava se realizando na encosta desta favela era algo admirável em termos de preservação e de respeito à natureza.

\section{O substrato moderno}

Saltamos dos pintores neoclássicos e românticos para a arte contemporânea, mas, no contexto do modernismo brasileiro, por exemplo, ao se analisar a vasta produção da primeira metade do século XX, nos perguntamos como a natureza passou a ser representada. Nas telas de Tarsila do Amaral, o Louvor à natureza não pode ser facilmente descolado do comprometimento 
maior com a ideia de uma brasilidade originária recuperada, fruto da retórica antropofágica. Não poderíamos deixar de revisar o clamor - Tupy or not Tupy? ao pensarmos na selva e nas estratégias artísticas de recuperação do estado de natureza exuberante. Na fase de sua maturidade e consagração pictórica, a artista alcança uma representação próxima a um realismo fantástico nos deixando imagens marcantes que, suspeitamos, tenha provocado Portinari a pintar "Fauna e flora brasileiras" (c. 1934), embora configurando regimes e sistemas distintos (ZILIO, 1997). O conteúdo paradisíaco da natureza [re] tratada nesta obra - não à toa escolhida para ser capa de publicação educativa sobre a exposição "Portinari - a arte e meio ambiente" (2014) -, cumpre notar, contrasta com outras obras e séries realizadas pelo artista dedicadas à floresta, dominadas por uma outra paleta e, possivelmente, intenção. Não obstante, em algumas destas imagens, onde as cores da terra de Brodósqui são reevocadas, a presença da arara vermelha na companhia de outros animais, convivendo de modo não natural, com suas anatomias destacadas em perfis, fruto, inclusive, de estudos preparatórios que denunciam tanto a sua formação acadêmica (PORTINARI, 2002), como muitas das suas escolhas. Neste sentido, poder-se-ia dizer que há uma preocupação e um olhar, em paralelo às questões nacionais e formais demandas à época, frutos de uma postura decidida e dedicada ao meio ambiente? Ou predomina o anúncio de um mundo natural reinventado, enfatizando-se as cores, as belezas naturais e as espécies de um Brasil cujo imaginário de um "paraíso tropical" é vendido e comercializado massivamente, de modo a vigorar, tal projeção, no mundo até hoje? Talvez o resultado de uma fronteira possível, dentro deste contexto, entre algum posicionamento ambiental e uma abordagem que reforçasse o sentimento de brasilidade, mediado pela reformulação das visualidades no país, não possa escapar, conjuntamente, da compreensão dos planos que participam das gêneses criativas destas obras...

Nos articulando ao que Canclini (2013) argumenta sobre a expansão dos limites e dos regimes comunicacionais em artes visuais, na fronteira entre arte e mídias, importante observar como a natureza vem sendo tratada e discutida pelo "vasto desdobramento do vídeo, das animações por computador" (p.51). Tal imaginário, portanto, que forja diversas hierarquias de uma natureza nativa, sobrevive no cinema em produções recentes, como nas cenas apresentadas nos filmes Rio 1 e Rio 2, realizados em computação gráfica, contando a história e as aventuras da arara-azul, no Rio de Janeiro e depois em território amazônico. Importante ressaltar que logo na cena de abertura desta animação lançada em 2011, temos contato com uma iconografia típica das pinturas do século XIX, lembrando os enquadramentos dos mencionados artistas viajantes. Na sequência imediata, um apoteótico musical que mimetiza os espetáculos da Broadway, abrindo-se ao desfile de 


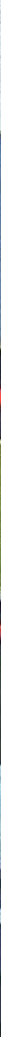

Figura 9

Candido PortinariFauna e Flora, 1934. Fonte: Caderno do professor - Exposição Portinari - a arte e meio ambiente..Disponível in https://www. ifsc.usp.br/portinari/ images/PDF/cad.prof. Ens.Fund.I.pdf. Direito de reprodução gentilmente cedido por João

Candido Portinari. inúmeros pássaros de uma colorida fauna tropical, onde cachos de banana se transformam em tucanos, dando-se destaque também aos voos acrobáticos das araras vermelhas, com a mesma plumagem exibida na obra de Portinari de 1934.

No caso das paisagens criadas por Tarsila, percebe-se um encontro com o sentimento que restabelece a meninice da artista, de uma infância feliz, onde a pintura se dá como brincadeira (ZILIO, 1997, p. 82). A natureza encontrada na obra desta artista de raízes caipiras possui uma dimensão mágica, observada no tratamento das plantas, nas distorções de volumes e proporções lúdicas, na combinação de tons vívidos e alegres, bem como no trânsito de suas memórias e vivências afetivas na fazenda em diálogo com o folclore brasileiro - leitura reproduzida pela animação Tarsilinha de Célia Catunda e Kiko Mistrorigo, em 2020. Assim, embora produzindo anúncios e sistemas distintos em seus encaminhamentos sobre a natureza, Portinari e Tarsila parecem estar mais comprometidos com a construção de uma brasilidade, envolvendo-se mais com as questões da identidade que sistematizaram uma época do que propriamente interessados em interações com o meio-ambiente, sem os contornos de uma intimidade crescente que encontramos nos dias de hoje.

Sabemos que hoje a prática de arte, seus formatos e sua comunicação se modificam no momento em que os artistas plásticos interagem com tecnologias audiovisuais e digitais." (CANCLINI, Op. cit., p.51)

Assim, ainda explorando o campo da cultura visual, atenta-se que algumas animações e produções fílmicas recentes, entre tantos exemplos, já vem apontando para outro paradigma, apresentando narrativas que lidam 
Figura 9

João Modé. Para o Silêncio das Plantas, 2011 . Modé faz vínculo com o repertório dos artistas cientistas e viajantes. Foto Wilton Montenegro. Imagem gentilmente cedida por artista e fotógra-

fo. Fonte: Catálogo da exposição Para o silêncio das plantas nas Cavalariças, EAV/ Parque Lage, RJ, 2012. com a temática ambiental de modo alarmante, talvez na tentativa de despertar nas crianças e adolescentes menos o sentimento de criticidade do que envolvê-las em um consumo comercialmente oportunista, diante das tragédias com as quais já convivemos. Assim, nestas produções são anunciadas e enfatizadas cidades feitas inteiramente de plástico e cimento, onde as pessoas "vivem" sem a presença de nenhuma árvore (Lorax: em busca da trúfula perdida, 2012); construções e edificações retratadas como vilãs, justamente por diminuírem e roubarem os espaços naturais de diversas espécies (Os Sem-floresta, 2006); futuros apocalípticos acentuando a imagem do planeta ainda mais devastado e agonizante do que em nossos dias, onde robôs cuidam do lixo e da natureza (Wall-E, 2008); as leis da natureza confrontadas aos sistemas de vida predatórios dos humanos (Bee Movie, 2007), entre outras produções audiovisuais voltadas para este público, ressignificando ou reorientando, de modo paradoxal, a própria indústria do entretenimento. Até mesmo a infância é capturada pela ansiedade quanto à catástrofe ambiental. 


\section{Conclusões vivazes: arte por outras naturezas possíveis}

Um outro futuro é possível na abertura ao diálogo com o mundo natural. Se a plataforma de João Modé nos leva à música para as plantas e elabora um percurso de sinestesias por imersão na floresta em presença ativa, Lia do Rio, por sua vez, nos faz ascender para a atemporalidade, nos convocando à imanente infinitude dos objetos na natureza que ela institui. As pedras, sementes, folhas e árvores são presenças elementares de uma outra botânica, ou mesmo, diremos, mais acertadamente, uma sua versão mais profunda. Ambos os artistas nos falam de um modo para a ampliação cognitiva, uma extensão perceptual hiperventilada, aberta, em condição de existência plenamente fluida e em estado comunicante.

No salto traçado entre artistas viajantes e os cultivadores/xamânicos/coletores, fizemos um salto sobre a modernidade, tempo de progresso violento e subjugação da vida, para o substanciar que se fabrica hoje, em situação de escuta. Entendemos que esses agenciamentos da arte nos trazem um retorno, uma retrogradação ao estado de vínculo com o ambiente da floresta que a desdobra como múltipla, por isso podem ser ditos como produzindo naturezas. Agindo sobre derivação, sempre bifurcando, criando outros circuitos. Não apenas o subverter a lógica nos dá esse caminho, mas também uma artesania do simples, porém composto, numa versão alternada da recepção com a produção, como requer Modé, um artista que se desdobra em carpinteiro, poeta, tecelão, botânico, desenhista e paisagista e convida o público para agir sobre esse lugar, para estar poeticamente com as plantas, comunicando-se musicalmente. Na versão Morrinho, temos o estado encantado da infância, na mini favela abrigada sob a mata que circula a comunidade e a ela quer proteger.

Não apenas naturezas diversas são elaboradas, mas uma humanidade outra é fabricada aqui. Um artista em transe para criar outros mundos. Gente que conversa com plantas, sentindo o seu silêncio. Pessoas que caminham ao redor de uma árvore para acessar a atemporalidade. Também as perenes crianças do Morrinho que nos chamam para brincar de polícia e bandido sob o que resta de uma mata.

Um futuro é redesenhado, desimpedido nos olhares e pelos demais sentidos suscitados nos ensaios plásticos que elencamos, vieses amplificados pelas redes sensoriais que evocam e que nos suspendem no tempo. Transcendência que afirma o pulso vital da arte, - ao contrário de negar a vida e estabelecer hierarquias estéticas, ou polir os cânones -, como ocorrera nos palácios da academia imperial que serviram para uma acomodação social, 
mais do que outra motivação ou nas expedições interesseiras seguindo os rastros das minas auríferas. Lembramos que, mesmo no passado, essa fuga à floresta já existiu, como ocorrera com Grimm, ao decidir abandonar a Academia Imperial de Belas Artes e destituir o canal oficial já superado, do envelhecido teor, abrindo novas frentes, criando uma escola própria para acessar o mundo natural a seu modo. Assim como, também, ocorrera, mesmo que relativamente, com anteriores pintores viajantes, tenazes aventureiros que souberam apreciar um repertório múltiplo de formas de vida e foram, alguns deles, como Rugendas e o jovem Adrien Taunay, rebeldes amantes das matas e dos rios.

Neste exato momento, nas bordas do abismo Antropoceno, vemos que as estratégias aqui refletidas nos levam, como linhas de força, a instituir novas formas de presença que possam estar vivazes e atuantes em um mundo em derrocada, a estabelecerem vínculos com outras naturezas/cultura e a criarem um ponto de ultrapassagem. Estratégias que possam, como bem expressa Zerbini (2020), pensar a natureza em relação ao futuro, evocando o passado.

\section{Referências}

CAMPOFIORITO, Quirino. História da pintura brasileira no século XIX. Rio de Janeiro: Edições Pinakotheke, 1983.

CANCLINI, Néstor Garcia. A Sociedade sem Relato: Antropologia e Estética da Iminência. São Paulo: Edusp, 2013.

CAUQUELIN, Anne. A invenção da paisagem. São Paulo: Martins Fontes, 2007.

DESCOLA, Philippe. Outras Naturezas, Outras Culturas. São Paulo: Editora 34, 2016.

DO RIO, Lia. Sobre a Natureza do Tempo. Rio de Janeiro: Editora F10, 2014.

HAN, Byu Chul. Favor fechar os olhos - em busca de um outro tempo. Petrópolis: Editora Vozes, 2021.

KRENAK, Ailton. Ideias para adiar o fim do Mundo. São Paulo: Companhia das Letras, 2019.

. A vida não é útil. São Paulo: Companhia das Letras, 2020.

LATOUR, Bruno. Jamais fomos modernos: ensaio de antropologia simétrica. São Paulo: Ed. 34, 2013. 
LATOUR, Bruno. Diante de Gaia: oito conferências sobre natureza e antropoceno. São Paulo: UBU editora, 2020.

LEVY, Carlos et Al. Iconografia e Paisagem. Coleção Cultura Inglesa. Rio de Janeiro: Edições Pinakotheke,1994.

LYRA, Edgar. "O Tempo das Coisas". In DO RIO, Lia. Sobre a Natureza do Tempo. Rio de Janeiro: Editora F10, 2014.

MODÉ, João. Para o silêncio das plantas / João Modé; [texto de Alexandre Sá]. - Rio de Janeiro: Automática, 2012. 140 p: il. Exposição realizada na Escola de Artes Visuais do Parque Lage, Rio de Janeiro, RJ, de 17 de dezembro de 2011 a 10 de abril de 2012.

MONTEIRO de CARVALHO, Anna Maria Fausto. Mestre Valentim. São Paulo: Cosac \& Naify Edições, 1999.

32a . Bienal de São Paulo: Incertezas Vivas. São Paulo: Fundação Bienal de São Paulo, 2016. ISBN 978-85-85288-56-2

PORTINARI, Candido. Pinturas e desenhos. Rio de Janeiro: Edições Pinakotheke, 2002. ISBN 85-7191-016-2

ROCHA, Lia de Mattos. Uma favela diferente das outras? Rotina, silenciamento e ação coletiva na favela do Pereirão. Rio de Janeiro: Quarter: Faperj, 2013.

SCHWARCZ, Lilia Moritz \& DIAS, Elaine (org). Nicolas-Antoine Taunay no Brasil: uma leitura dos trópicos. Rio de Janeiro: Sextante, 2008.

ZERBINI, Luiz. In CRIOART. (Nota da Redação). Oi Futuro reabre com grande exposição de Luiz Zerbini In https://www.crio.art/oi-futuro-reabre-com-grande-exposicao-de-luiz-zerbini/ Acesso em julho de 2020.

ZILIO, Carlos. A Querela do Brasil: a questão da identidade da arte brasileira. Rio de Janeiro: Relume-Dumará, 1997.

Artigo recebido em 08 de julho de 2021 e aceito em 30 de julho de 2021.

Este é um artigo publicado em acesso aberto sob uma licença Creative Commons (cc) $\mathbf{B r}$ 